\title{
Chronic non puerperal uterine inversion due to submucosal fibroid: a rare case report
}

\author{
Shirish Dulewad, Chitikala Haritha*
}

Department of Obstetrics and Gynecology, Dr. S. C. G. M. C, Nanded, Maharashtra, India

Received: 25 December 2019

Revised: 24 January 2020

Accepted: 29 January 2020

\author{
*Correspondence: \\ Dr. Chitikala Haritha, \\ E-mail: harithachitikala@gmail.com
}

Copyright: () the author(s), publisher and licensee Medip Academy. This is an open-access article distributed under the terms of the Creative Commons Attribution Non-Commercial License, which permits unrestricted non-commercial use, distribution, and reproduction in any medium, provided the original work is properly cited.

\begin{abstract}
Chronic uterine inversion is a very rare and often difficult to distinguish between uterovaginal prolapse, submucous fibroid and cervical fibroid. Its diagnosis is based on high index of suspicion. A 50-year-old Para-3Live-3 tubectomised postmenopausal women with k/c/o psychiatric illness, resident R/0 Jambhrun, Mudhkhed came to our hospital with a complaint of irreducible mass protruding per vaginum since 2-3 months duration Subsequently vaginal hysterectomy has been done. The certainty of diagnosis of inverted uterus reached intraoperatively. Gross examination of cut uterus showed fundally located sub-mucous fibroid and specimen sent for histo-pathological report. Non puerperal chronic inversion of uterus is rare condition occurring in approximately $17 \%$ of all uterine inversions and most uterine inversions are acute and puerperal. Its incidence is $1 / 30,000$ deliveries and is considered a serious complication of child birth. Most common factor causing inversion -> prolapse and extrusion of fibroids1 especially submucous myoma of fundus (80-85\%). Its diagnosis should be considered at any age in post-menopausal period. Superinfection of the infected part should be suspected and treated with appropriate broad-spectrum antibiotics before the surgery.
\end{abstract}

Keywords: Certainity of diagnosis intraoperatively, Chronic non puerperal uterine inversion, Hysterectomy, Submucosal fibroid

\section{INTRODUCTION}

Uterine inversion is a rare clinical condition with only a few cases of chronic non-puerperal inversion of uterus quoted in the literature. On an average a gynaecologist may only see one case in their lifetime. Uterine infection is described as a part of the uterus indenting towards and eventually prolapsing through the dilated cervix resulting in uterus being turned inside out. It is categorized as puerperal and non-puerperal complication. ${ }^{1}$ Acute puerperal uterine inversion occurs within 24 hours of birth, sub-acute inversion occurs after 24 hours and within 4 weeks, chronic occurs after 4 weeks. ${ }^{2}$ Surgery for inverted uterus is technically difficult and poses a great challenge for the surgeon. Authors are reporting a case of chronic non-puerperal uterine inversion due to benign submucous fundal uterine fibroid in 50-year-old multiparous women who had correction of anaemia followed by vaginal hysterectomy.

\section{CASE REPORT}

A 50-year-old multiparous women was admitted in our hospital after being referred from one of the surrounding private hospitals misdiagnosed to be infected polyp with prolapse. She presented with a chief complaint of mass per vagina for 2-3 months duration for it to become painful associated with lower abdominal pain, vaginal discharge which was tinged with blood and with easy fatigability. She has no fever, rigors or chillness. The 
mass was irreducible, painful, with difficulty in urination and vaginal discharge. She had difficulty in both walking and sitting position. There was also history of dyspnoea on exertion and easy fatigability. She had a history of chronic cough when suffered from pulmonary tuberculosis 6 years ago, however she had undergone complete course AKT of 6 months. Two of her deliveries were conducted at a civil hospital while her last delivery was conducted at home assisted by traditional birth attendant. She attained menopause 4 years ago and there is no history of post-menopausal spotting or bleeding. She was not a known diabetic or hypertensive patient. She had history of psychiatric illness which got aggravated due to her recent condition.

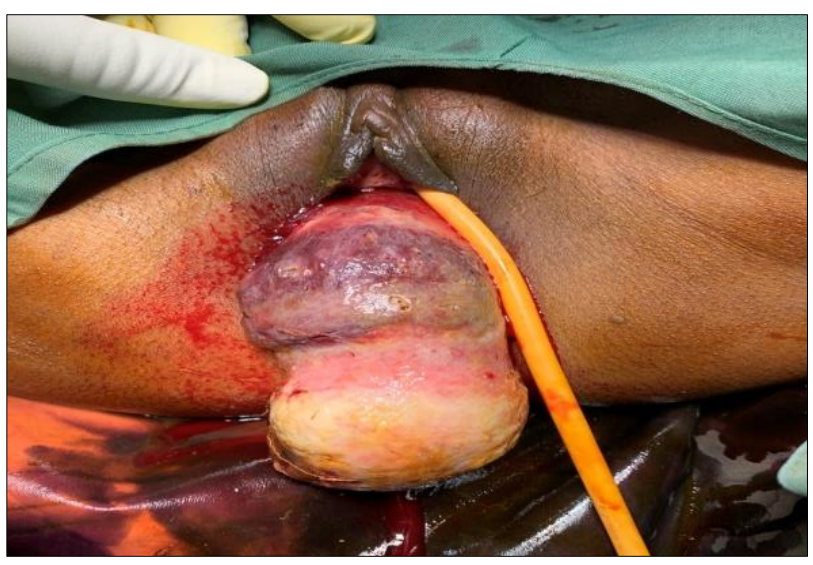

Figure 1: Preoperative.
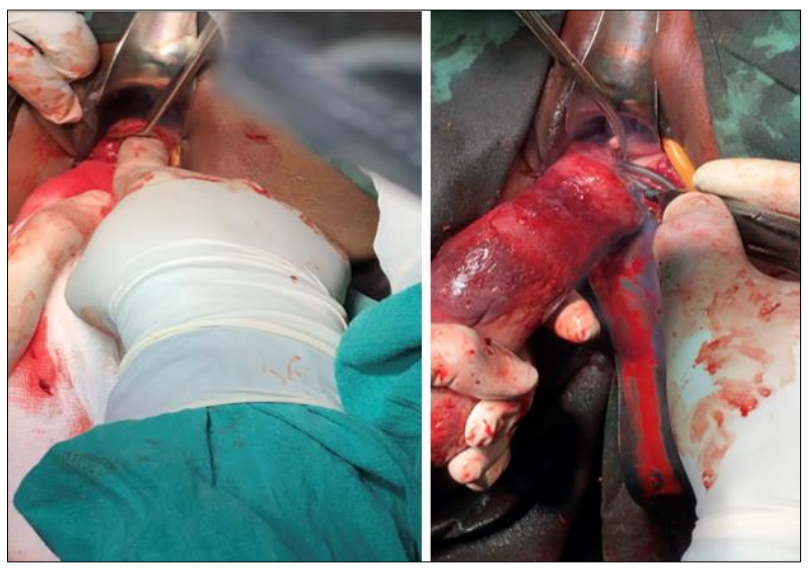

Figure 2: Palpation by pinch method and removal of mass.

On examination, her general condition was poor, thinly built and pale. Her other systemic examination is normal. Further, on local examination, there was a large fleshy ulcerated and infected mass protruding through introitus with leading edge of mass, globular in shape of about $7 \times$ $6 \mathrm{~cm}$ in dimension. On palpation, mass was tender and firm which bled on touch. Cervix could not be delineated, cervical os could not be identified and no pelvic mass or uterus felt.
The lab investigations showed haemoglobin level was 5 $\mathrm{g} / \mathrm{dl}$ so 3 units of blood were transfused and correction of anaemia was done. Rest of the investigations were within normal limits. On ultrasound of abdomen and pelvis, uterus was low-lying and features suggestive of uterovesical prolapse is documented.

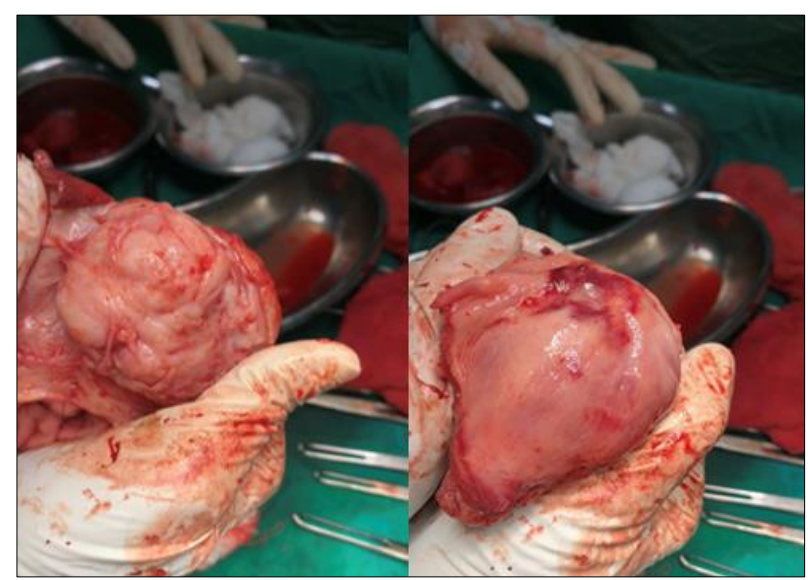

Figure 3: Gross specimen showing inverted uterus and fundal submucous fibroid.

Suspecting as a case of uterine inversion, patient had undergone primary anaesthetic evaluation for major surgery. After correcting anaemia and complete coverage of broad-spectrum antibiotics, patient had been examined under anaesthesia and further procedure of vaginal approach has been decided.

The route of operation could be abdominal or vaginal or by combined abdo and vaginal approach. But in this institute, decision of vaginal hysterectomy has been taken by the operating surgeon.

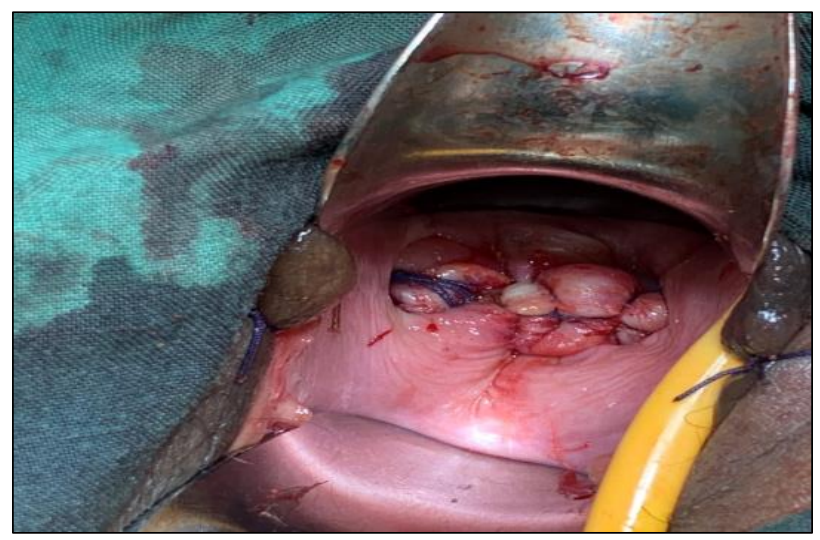

Figure 4: Vault closure at the end of surgery.

Patient is placed in semi-lithotomy position, foleys catheter is introduced. On per vaginal examination uterus is not felt and appears to be as procidentia (Figure 1). The last boundary of inversion part is palpated by pinch method (Figure 2) and decision of opening of anterior and posterior pouches had been taken intraoperatively 
and by a single clamp, all the supports of uterus have been cut, ligated and vaginal hysterectomy has been done. The gross specimen was cut and evidence of fundal submucosal fibroid was found and sent for histopathological examination (Figure 3). The surgery ended successfully with vault closure and minimal blood loss (Figure 4).

Per operative blood loss was approximately $100 \mathrm{ml}$. The post-operative period was uneventful and patient was discharged on day 5 and appointed for re-evaluation on post-operative day 30 . At the time of discharge, her general condition is improved including her psychiatric state.

\section{DISCUSSION}

Non puerperal uterine inversions are usually chronic and precipitated by tumours sited at the fundus of the uterus which exert traction force causing it to get inverted. However, uterine inversion is also reported with no association with tumours. ${ }^{3}$

The major factors which contribute to its occurrence are tumour attachment site, thickness of tumour pedicle, thin uterine wall and dilatation of cervix. ${ }^{4}$

The diagnosis is very difficult and needs high index of suspicion. This is the first reported case in this hospital in 50 -year postmenopausal women. Thus, in a patient with vaginal mass, authors should not forget to see for uterine inversion. ${ }^{5}$ This case has superinfection of the prolapsed part which was treated with broad spectrum antibiotics and histopathological report revealed dense chronic inflammation with necrosis. Chronic non puerperal uterine inversion is a rare condition which is difficult to manage and in most of the cases misdiagnosed as carcinoma cervix or $3^{\text {rd }}$ degree UV prolapse or endometrial polyp. ${ }^{6}$ Certainty of diagnosis is usually obtained intraoperatively in most of the cases. However, MRI and CT scan have been shown to be useful in diagnosing this type of case. ${ }^{7}$

\section{CONCLUSION}

Chronic nonpuerperal uterine inversion is a very rare phenomenon and its diagnosis is often missed. Careful evaluation, ruling out the other differential diagnosis, a challenging surgery is often needed in diagnosing and treating this case.

Funding: No funding sources

Conflict of interest: None declared

Ethical approval: Not required

\section{REFERENCES}

1. Takano K, Ichikawa Y, Tsunoda H, Nishida M. Uterine inversion caused by uterine sarcoma: a case report. Jpn J Clin Oncol. 2001;31:39-42.

2. Shabbir S, Ghayasuddin M. Chronic non puerperal uterine inversion secondary to sub-mucosal fibroid. J Pak Med Assoc. 2014;64(5):586-8.

3. Salameh AE, Aljaberi LM, Almarzooqi RM, Khloof DR, Ras SA, Tabanja R. Non-puerperal uterine inversion associated with adenosarcoma of the uterus: a case report. Case Reports Women's Health. 2019;22:e0107.

4. Krenning RA, Dörr PJ, De Groot WH, De Goey WB. Non-puerperal uterine inversion. Case report. Int $\mathbf{J}$ Obstet Gynaecol. 1982;89(3):247-9.

5. Fofie C, Baffoe P. Non puerperal uterine inversion: A case report. Ghana Med J. 2010;44:79-81.

6. Kilpatrick CC, Chohan L, Maier RC. Chronic nonpuerperal uterine inversion and necrosis: a case report. J Med Case Reports. 2010;4(1):381.

7. Lewin JS, Bryan PJ. MR imaging of uterine inversion. J Comput Assist Tomogr. 1989;13:357-9.

Cite this article as: Dulewad S, Haritha C. Chronic non puerperal uterine inversion due to submucosal fibroid: a rare case report. Int J Reprod Contracept Obstet Gynecol 2020;9:1285-7. 